takes green or gray, or one alone, with or without purple, he is completely green-blind. If he takes red or orange, with or without purple, he is violet-blind. If there be any doubt, the examinee may be subjected to a third test, which is not necessary for the satisfaction of an expert, but which sometimes strengthens the proof in the eyes of a bystander. The pattern for this third test is a skein of bright red, to be used in the same way as the green and the purple. The red-blind iselects for this dark greens and browns, which are much darker than the pattern; while the green-blind selects greens and browns which are lighter than the pattern.

The method of examination thus described is, I believe absolutely trustworthy. It requires no apparatus beyond the bundle of skeins of wool, no arrangements beyond a room with a good window, and a table with a white cloth. In examining large numbers of men, they may be admitted into the room fifty or so at a time, may all receive their instructions together, and may then make their selections one by one, all not yet examined watching the actions of those who come up in their turn, and thus learning how to proceed. The time required for large numbers averages about a minute a person. I have heard and read of instances of colour-blind people who had passed the wool test satisfactorily, and had afterwards been detected by other methods, but I confess that I do not believe in them. I do not believe that in such cases the wool test was applied properly, or in accordance with Holmgren's very precise instructions; and I know that it is often applied in a way which can lead to nothing but erroneous results. Railway foremen, for example, receive out of store a small collection of coloured wools selected on no principle, and they use it by pulling out a single thread, and by asking the examinee, "What colour do you call that?" Men of greater scientific pretensions than railway foremen have not always selected their pattern colours accurately, and have allowed those whom they examined, and passed, to make narrow comparisons between the skeins in all sorts of lights, in a way which should of itself have afforded sufficient evidence of defect.

Although, however, the expert may be fully satisfied by the wool test that the examinee is not capable of distinguishing with certainty between red and green flags or lights in all the circumstances in which they can be displayed, it may still remain for him to satisfy the employer who is not an expert, the railway manager, or the ship-owner, and to convince him that the colour-blind person is unfit for certain kinds of employment. It may be equally necessary to convince other workmen that the examinee has been fairly and rightly dealt with. Both these objects may be easily attained, by the use of slight modifications of the lights which are employed. Lanterns for this special purpose were contrived, some years ago, by Holmgren himself, and by the late Prof. Donders of Utrecht, and what are substantially their contrivances have been brought forward within the last few months as novelties, by gentleman in this country who have re-invented them. The principle of all is the same-namely, that light of varying intensity may be displayed through apertures of varying magnitude, and through coloured glass of varying tints, so as to imitate the appearances of signal lamps at different distances, and under different conditions of illumination, of weather, and of atmosphere. To the colour-blind, the difference between a red light and a green one is not a difference of colour, but of luminosity; the colour to which he is blind appearing the less luminous of the two. He may therefore be correct in his guess as to which of the two is exhibited on any given occasion, and he is by no means certain to mistake one for the other when they are exhibited in immediate succession. His liability to error is chiefly conspicuous when he sees one light only, and when the conditions which govern its luminosity depart in any degree from those to which he is most accustomed. With the lanterns of which I have spoken, it is always possible to deceive a colour-blind person by altering the luminosity of a light without altering its colour. This may be done by diminishing the light behind the glass, by increasing the thickness of the red or green glass, or by placing a piece of neutral tint, more or less dark, in front of either. The most incredulous employer may be convinced, by expedients of this kind, that the colourblind are not to be relied upon for the safe control of ships or of locomotives. With regard to the whole question, there are many points of great interest, both physical and physiological, which are still more or less uncertain but the practical elements have, I think, been well-nigh exhausted, and the means of securing safety are fully in the hands of those who choose to master and to employ them. The lanterns, in their various forms, are useful for the purpose of thoroughly exposing the colour-blind, and for bringing home the character of their incapacity to unskilled spectators; but they are both cumbrous and superfluous for the detection of the defect, which may be accomplished with far greater ease, and with equal certainty, by the wool test alone.

I have already mentioned that the examinations which have been conducted in the United States, thanks to the indefatigable labours of Dr. Joy Jeffries, have led to the discovery of an enormous and previously quite unsuspected amount of colour-ignorance, the condition which is frequently mistaken for colour-blindness by the methods of examination which are in favour with railway companies and with the Board of Trade; and this colourignorance has been justly regarded as a blot on the American system of national education. It has therefore, in some of the States, led to the adoption of systematic colour-teaching in the schools; and, for this purpose, Dr. Joy Jeffries has introduced a wallchart and coloured cards. The children are taught, in the first instance, to match the colours in the chart with those of the cards distributed to them; and, when they are tolerably expert at matching, they are further taught the names of the colours. It must, nevertheless, always be remembered that a knowledge of names does not necessarily imply a knowledge of the things designated; and that colour-vision stands in no definite relation to colour-nomenclature. Even this system of teaching may leave a colour-blind pupil undetected.

\section{COMPOUND LOCOMOTIVES.}

$\mathrm{THE}$ present position of locomotive engineering in this country is of a very interesting nature; owing to the gradual increase of weight of trains hauled and the higher speeds now in use, it has been necessary to increase the power of the locomotive by leaps and bounds to cope with these demands. This naturally has not been done without great scheming on the part of the designers, for, with the standard gauge of railway of 4 feet $8 \frac{1}{2}$ inches, the engines are tied down to certain dimensions between the frame plates; in total length, to a certain extent, by the turntables in use; and in height of boiler for reasons of stability. These questions of design are interesting because they are intimately connected with the economical working of the engines, especially in the consumption of fuel, a question which of late years has taken a prominent position in the economical management of locomotives. For several years the highly economical results obtained at sea with the use of high pressures coupled with the compound or triple expansion engine have caused engineers to look in that direction for further improvements, with the result that two different types of compound locomotives were designed, and are considerably past the experimental stage. These engines are now working successfully on two of the English railways, and are being adopted on many foreign ones. 
The type of compound locomotives first used in any number is that patented by Mr. F. W. Webb, the able Mechanical Superintendent of the London and NorthWestern Railway. This design is interesting because it is to a certain extent an example of really original work in locomotive practice. Mr. Webb had several very good ideas to work on in this design, all of very great importance from an engineer's point of view. These ideas were as follows:- The engine must not have a double-throw crank-axle, this being certainly the weak point of all inside-cylinder engines; the coupling rods between driving and trailing wheels must be done away with, since these also sometimes break, and may cause serious accidents. The doing away with the coupling rods enables a longer fire-box to be used, because the coupled wheels should be near together to obtain a minimum length of coupling rod, for reasons of safety. Thus, to design an engine to be more powerful than an ordinary four-coupled express of the North-Western heavy pattern, and having at the same time fewer parts liable to accident, as stated above, requires some clever scheming and much thought. The engine ultimately adopted by Mr. Webb for use on the London and North-Western Railway has three cylinders, viz. two high-pressure cylinders and one lowpressure cylinder. The high-pressure cylinders are placed one on each side of the engine, and are connected to the trailing or hind pair of wheels. The low-pressure cylinder is placed between the frames at the front end of the engine, and is connected with the front pair of driving wheeis by a single-throw crank-axle. It will be noticed that in this arrangement each pair of wheels are driving wheels, that the side or coupling rods are done away with, and that the ordinary double-throw crank-axle has given place to a single-throw crank-axle, which may be made of ample dimensions and practically unbreakable. The course of the steam through the cylinders is easily understood: steam passes from the boiler to each high-pressure cylinder, and, after doing a certain amount of work, it is led from each high-pressure cylinder into the steam-chest of the low-pressure cylinder; it is there expanded down to a still lower pressure, and then exhausted finally up the chimney.

The cylinders of the Dreadnought type-that is, the most powerful type of the compounds on the London and North-Western Railway - are: high-pressure cylinders, I4 inches in diameter and 24 inches stroke; the lowpressure cylinder has a diameter of 30 inches and 24 inches stroke. These engines are designed in such a manner that, when working at their usual speed, the power developed by the high-pressure cylinders, and applied through the hind pair of wheels, shall be about equal to the power of the low-pressure cylinder, and applied to the front pair of driving wheels.

Through the kindness of Mr. Webb I am able to give an account of the working of a special train, run in order to test the fuel and water consumption of this class of engine.

On April 17, I887, the engine Dreadnought, No. 503, worked a special train of coaches and dynamometer car from Crewe to Wolverton, a distance of $105 \frac{3}{4}$ miles, at a speed of 24 miles per hour, including stoppages, which were made every 15 miles on the journey; 24 cwt. of coal were put into the fire-box during the trip, which gives a consumption of 25.4 lbs. of coal per mile ; 2629 gallons of water were evaporated, which equals $9^{\circ} 78 \mathrm{lbs}$. of water per pound of coal consumed. The weight of the train, exclusive of engine and tender, was 259 tons, 3 cwts. 3 qrs, and the mean weight of engine and tender 62 tons I 3 cwts., or a total of 32 I tons 16 cwts. 3 qrs. for the whole train. This is equivalent to 4.13 tons of train hauled to $I$ ton of engine and tender hauling it, and $I \cdot 26 \mathrm{oz}$. of coal per ton per mile.

The same locomotive worked a similar train between the same points on January I, I 888, but at a speed of 44 miles per hour, with one stoppage only at Rugby, the results being as follows:-30 cwts. of coal were put into the fire-box during the trip, which gives a consumption of $4 \mathrm{I} \cdot 3 \mathrm{lbs}$. of coal per mile; 3608 gallons of water were evaporated, which equals $8: 26$ ibs. of water per pound of coal consumed. The weight of the train, exclusive of engine and tender, was 256 tons, $18 \mathrm{cwts}$, and the mean weight of the engine and tender 62 tons I 3 cwts., or a total of 319 tons II cwts. for the whole train. This is equivalent to $4 \cdot I$ tons hauled to $I$ ton of engine and tender hauling it, and $2^{\circ} \mathrm{c} 6 \mathrm{oz}$. of coal per ton per mile.

When the first trip was made, the weather was warm and dry, but during the latter a hard frost prevailed. With this exception the conditions under which the trips were made were practically alike. The difference in fuel consumption between the two trips may be taken as that due to the difference in speed. There are 77 compound locomotives now at work on the London and NorthWestern Railway, which have run to the end of December I 889 a total of $13,423,798$ miles, and several more of the same type are now being built at Crewe Works.

It will be observed that in the Webb type of compound locomotive the design is such that the sizes of the cylinders can be easily increased if necessary to obtain a still more powerful engine, provided, of course, a larger boiler is used, and there is no reason why even the Dreadnought should not be the forerunner of still more powerful compounds on the London and North-Western Railway when their use becomes a necessity. It is evident that the use of a third cylinder, with motion and gear, must entail a greater cost for repairs as well as a larger consumption of oil when at work, and that the type of engine does not easily lend itself to a speedy and economical rebuild of ordinary locomotives to the Webb compound type; the system, therefore, is one quite unique in its way, and unlike any of the earlier attempts at compounding locomotives.

Another successful design of compound locomotives is that due to Mr. T. W. Worsdell, the Locomotive Engineer of the North-Eastern Railway, on which railway a large number of compound locomotives are at work. The Worsdell compound is the outcome of many experiments both at home and abroad. There are two cylinders used, and to all appearances the locomotives are similar to the ordinary non-compound locomotive. These two cylinders are of different diameters, and the steam, after doing work in the smaller one, is exhausted into the steam-chest of the larger or low-pressure cylinder, where it is further reduced in pressure by expansion in the cylinder, and afterwards is exhausted. It will be observed that in the Webb system there are two highpressure cylinders connected to the hind pair of wheels, with the crank-pins, of course, at right angles, and that the low-pressure piston receives no steam from the highpressure cylinders until the engine has commenced to move. Thus, all the work of starting the train for the first few revolutions of the driving wheels has to be done by the high-pressure pistons, and these are always able to start, in whatever position the wheels may be, because they are in duplicate and have no dead point. In the Worsdell system this is not possible without some special appliance, and it is this particular appliance which constitutes the patented device in the engine which makes it the success it is. In any two cylindered compound engine with cranks at right angles, which is the usual practice, it is possible to easily observe that there are two positions from which the engine cannot start on the admission of steam, because the admission of steam to the low-pressure cylinder depends on the exhaust from the high-pressure cylinder, and the high-pressure piston may happen to be at exactly the end of its stroke, either at the front or the back end-known as being on the centre or dead points. As the Worsdell engine is constructed with two cylinders, as before stated, it will be 
interesting to know how the difficulty has been got over. When the high-pressure piston is at the end of its stroke, the low-pressure piston will be at the middle of its stroke, the cranks being at right angles; and if by any means steam could be admitted to the low-pressure cylinder without affecting the high-pressure piston, the engine would, of course, be able to turn round half a revolution, and so place the high-pressure piston immediately in a position to commence its stroke. The "intercepting valve," as it is called, is an arrangement by which the passage between the high- and low-pressure cylinders can be closed, and at the same time admits steam to the low-pressure cylinder when the high-pressure piston is on one or other of its dead points. This arrangement consists of a valve in the passage between the cylinders connected to a small piston in a cylinder placed in a suitable position. The steam supply is taken from the main steam-pipe, and regulated in its passage to the small cylinder by a valve worked from the foot-plate. If the engine refuses to start when the regulator is opened, the lever connected to the intercepting valve apparatus is pulled over. This admits steam behind the small piston, which immediately is forced forward and closes the intercepting valve, at the same time opening a port through which the steam is admitted to the low-pressure cylinder. This starts the engine, and the lever is returned to the running position by means of a spring. The rise of pressure in the passage between the cylinders, owing to the exhaust from the high-pressure cylinder, opens the intercepting valve, and compound working commences. This arrangement is very simple and trustworthy in practice. A large number of Worsdell compounds are now in use in India and elsewhere with admirable results. Where coal costs forty shillings and more per ton, it is very important that the most economical engine should be used.

On the Brighton Railway very economical results have long been obtained with the ordinary locomotives designed by the late $\mathrm{Mr}$. Wm. Stroudley, and are due to the general excellence of design of boiler and engine, coupled with careful driving, induced by the coal premium. If locomotives were generally worked more by the reversing lever and less by the regulator, more economical results would be recorded; or, in other words, expansive working means economical working, which in the ordinany engine depends on the driver. In this manner, to work steam expansively in the non-compound locomotive, it is necessary for the driver to regulate the power of the engine by varying the quantity of steam used in the cylinders by means of an earlier or later cut-off, regulated by means of the reversing gear, the supply from the boiler not being checked in any way when rumning. On the other hand, the engine can be regulated by varying the steam supply at the regulator, the degree of expansion in this case being such as the driver chooses to generally use. Under the first conditions all the steam used is worked expansively, and under the latter the cylinders are choked with steam at one minute, and have an insufficient supply at the next. On the other hand, with the compound engine the steam must be expanded to a certain extent whether the driver likes it or not, and a result may be obtained with careless driving from the compound which would be passable when shown by a fairly well driven ordinary engine.

Mr. Drummond, the Locomotive Superintendent of the Caledonian Railway, has been making extensive experiments with steam-pressures varying from 150 to 200 lbs. per square inch, with identical engines doing practically the same work, the results of which will be given to the Institution of Civil Engineers. Without dealing with the practical difficulties involved in the use of such high pressures in non-compound locomotives, it will be highly interesting to know the results of these experiments. Whether the saving in fuel will equal or exceed the com-
Found results obtained by Messrs. Webb and Worsdell is a moot point.

It has been observed that the saving of fuel due to a compound locomotive when working similar trains with the non-compound engine is due to the higher pressure used, and that when the pressure is reduced to the same level as that used in the non-compound engine the saving in fuel at once drops considerably, and the results give a little saving in favour of the compound. From this it is evident that to alter an ordinary engine to the compound system, without raising the working pressure, will be of little good, and not worth the cost.

The many statements made in order to prove the more economical working of the compound over the noncompound locomotive are misleading in the extreme, and as a fair comparison of the two types they are of no value. The compound locomotives have large boilers, ample heating surface, and all recent improvements, besides the all-important feature of a working pressure of I75 lbs. per square inch. This engine is compared with an ordinary non-compound locomotive having a smaller boiler, generally hard pressed for steam, because it has to haul its maximum load, with a working pressure of about 150 to $160 \mathrm{lbs}$. to the square inch. To put two such engines into competition is absurd, and therefore the results obtained by the compound locomotives in everyday working cannot fairly be compared with the noncompound engine's records.

For these and other reasons engineers are anxiously waiting to learn the results of Mr. Drummond's experiments, for then for the first time will it be possible to fairly compare the two systems.

It must not be imagined that because the compound and triple expansion marine engine is so successful in fuel economy, the compound locomotive is also likely to be so: the conditions of working are so totally different; for instance, the engines of an Atlantic liner work for seven or more days, doing practically the same amount of work the whole time, and since the work is constant the engines are designed to do that work in the most economical manner. With the locomotive, on the other hand, the work is never constant, and for that reason the steam supply is an ever-varying quantity, besides the constant stopping and reversing always going on when any shunting has to be done. These conditions are fatal to very economical working, and more especially when applied to a compound locomotive.

The compound principle is a sound one, but one not likely to be generally adopted, on account of extra complication. The present consumption of fuel by ordinary well-designed non-compound locomotives (take, for instance, the Brighton average consumption of 24.75 lbs. per mile for all their passenger engines) has not been beaten by the compound locomotive records; and until it can be demonstrated that a distinct economy is possible by their general use, they are not likely to increase largely in number.

N. J. L.

\section{NEW ZOOLOGICAL PARK AT WASHINGTON.}

BY an Act of Congress passed on March 2 last year, an "appropriation" was made for the establishment of a Zoological Park in the district of Columbia "for the advancement of science and the instruction and recreation of the people." The control of the establishment was intrusted to a Commission composed of the Secretary of the Interior, the President of the Board of Commissioners of the District of Columbia, and the Secretary of the Smithsonian Institution.

Although the Commission was thus established only a year ago, the three Commissioners have already set to work, and, as we learn from their report, transmitted in January last to the Senate and House of Representatives 